\title{
Cervical Cancer Screening amongst Female Nursing Students in a Tertiary Institution, in South South Nigeria
}

\author{
Regina Etita Ella ${ }^{1}$, Emon Duke $^{1}$, Ekpoawan Esienumoh ${ }^{1}$, \\ Victoria Nyah $^{1} \&$ Victoria Kalu Uka ${ }^{1}$ \\ ${ }^{1}$ Department Of Nursing Science, Faculty of Allied Medical Sciences, College of Medicine, University of \\ Calabar, Cross River State, Nigeria \\ Correspondence: Regina Etita Ella, Department Of Nursing Science, Faculty of Allied Medical Sciences, College \\ of Medicine, University of Calabar, Cross River State, Nigeria. Tel: 234-803-358-262. E-mail: \\ retila07@yahoo.com
}

Received: November 7, 2019 Accepted: November 25, 2019 Online Published: December 30, 2019

doi:10.5539/gjhs.v12n1p165

URL: https://doi.org/10.5539/gjhs.v12n1p165

\begin{abstract}
Introduction: Developing countries have more challenges of cervical cancer among young women of reproductive age group. Good knowledge and practices of cervical cancer screening (CCS) among nursing students who graduate to become professional nurses can reduce the escalating incidence and high mortality among Nigerian women.
\end{abstract}

Methods: The study examined knowledge, attitude and practice of cervical cancer screening among female undergraduate nursing students in Department of Nursing Science, University of Calabar, Nigeria. Using simple random sampling technique a sample size of 212 nursing students was selected. Data was collected through a researchers developed and validated questionnaire titled Undergraduate nursing students knowledge attitude and practice of cervical cancer screening questionnaire (UNSKAPCCSQ). Simple frequencies and percentages were used to analyze data.

Results: Undergraduate nursing students had good knowledge (93.3\%) of cervical cancer screening. The students exhibited poor attitude towards cervical cancer screening as only (26.7\%) displayed positive attitude, while majority $(73.3 \%)$ did not find it necessary to screen. Only $(5 \%)$ had been screened for cervical cancer while (95\%) did not undergo any screening test.

Conclusion: Female undergraduate nursing students' good Knowledge of cervical cancer screening did not translate to positive attitude and practice. Cervical cancer screening education should be intensified for nursing students. CCS should be a mandatory exercise for all newly admitted female undergraduate in the university. Nursing students should be made to participate actively in raising awareness on cervical cancer screening and management.

Keywords: cervical cancer, knowledge, screening practices, female nursing students, tertiary institution

\section{Introduction}

Cervical cancer (CC) is an issue of great public health concern due to its increasing incidence and high mortality despite the fact that it is the most easily preventable cancer (Ebughe, Ekanem, Omoronyia et al., 2016). Evidence suggest that the increasing incidence is associated with poor attitude towards the preventive practices among nurses who are supposed to be custodians of health education preventive practices in general and for cervical cancer screening (CCS) in particular. If so then nursing students while in school need to be highly aware and knowledgeable about CCS and develop positive attitude for the practices. Cervical cancer is of high prevalence among women worldwide and accounts for about 300,000 deaths every year (World Health Organization (WHO), 2018). Cervical cancer is of high prevalence developing countries (Randall \& Ghebre, 2016; Small et al., 2017). It is expected that cervical cancer may account for more than $95 \%$ of all cervical cancer related death by 2030 in these countries (Cervical Cancer Action (CCA), 2011). This poses a serious burden to the reproductive health of women worldwide and society at large (Kieti, 2016).

Cervical cancer is mostly diagnosed in women between the ages of 35 and 44 (American Cancer Society (ACS), 2016). Adewole et al. (2016) opined that every ten minutes, two women die from cervical cancer. Report from the 
International Agency for Cancer Research and Control (IARC, 2017), show that cervical cancer is of high prevalence among Nigerian women. Allan (2015) further posited that cervical cancer is responsible for $65.7 \%$ of female related cancers in Northern Nigeria with Maiduguri recording an incidence of $72.6 \%$. In Calabar, Nigeria, the age specific incidence has been recorded as 20 per 100,000 with an average annual increase incidence rate of $12.1 \%$ (Ebughe et al., 2016). Despite the Federal Ministry of Health (FMOH) of Nigeria's establishment of CCS and human papilloma virus (HBV) preventive centers for the uptake of primary preventive measures in girls of 915 years, the level of execution and uptake of this plan is still questionable.

Poor knowledge and lack of positive attitude for effective screening exacerbates the situation to adequately respond to the rising incidence and this contributes to late presentation.

In an environment like Nigeria's, where late presentation is common, and where most cervical cancers are only detected by women when symptoms begin to manifest, there is need for adequate knowledge and positive attitude to the practice of cervical cancer screening by health workers especially nurses and nursing students in training who will in turn health educate the populace. Nurses and other health workers play an integral role in disease prevention and health promotion in the society because they are at forefront of health education. It is expected therefore that they possess adequate and current knowledge, sustain a good attitude and practice for health preventive practices in general and for cervical cancer screening in particular; only then can they effectively play their role. The World Health Organization, (2018) affirms that the high mortality rate from cervical cancer globally could be reduced through a comprehensive approach that includes effective screening for prevention, early diagnosis, and treatment programmes.

It is assumed that if nursing students who transit through university education to become nurses are adequately informed and trained to maintain positive outlook towards cervical cancer screening, they may also be able to positively influence healthcare consumers and other members of the society to do same. It is therefore of interest to the researchers to investigate female undergraduate nursing students knowledge, attitude and practice of towards cervical cancer screening in Department of Nursing Science, Calabar, Nigeria.

Cervical cancer is an uncontrollable proliferation of abnormal cells in the epithelium covering the tip of the cervix with rapid multiplication, infiltration and destruction of other cells, tissues and even organs resulting in the ulceration of the cervix associated with bleeding and excruciating pain (NCI, 2009). Cervical cancer is a rare outcome of a sexually transmitted infection and it is associated with a limited number of viral strains of the HPV family (National Cancer Institute NCI, 2015). The American Society of Clinical Oncology (ASCO), 2018) states that the most important risk factor for cervical cancer is infection with Human Papillomavirus. Over $70 \%$ of all cervical cancer is linked to two strains of HPV, HPV 16 and HPV 18 (NCI, 2015; ACS, 2016; CDC, 2017) (ACS, 2016; Cancer Research UK (CR-UK), 2017).

With early detection, cervical cancer can be treated (ASCO, 2018; Sasieni, Castanon, Cuzick, \& Snow, 2009). There are various methods of screening which include use of Papanicolaou cytological test (Pap smear), HPV test and visual inspection with acetic acid (VIA) or Lugol's iodine (ASCO, 2018; AbdAllah, Hummeida, \& Elmula, 2016; NCI, 2015). The Centre for Disease Control and Prevention (2018, WHO, 2013) recommends pap's smear every 3 years for women aged $21-29$, while older women should do Pap test and HPV test every 5 years. The HPV test uses the same method as the Pap smear in obtaining samples but instead of exploring the cells for signs of abnormality, it looks for high risk HPV types that are implicated in cervical cancer (Siferlin, 2014; Campana, 2017). Health workers in general and Nurses in particular play an integral role in disease prevention and health promotion. They can influence adherence and health activities among most women; Therefore knowledge of cervical cancer screening is important so as to promote informed decisions about cervical cancer screening.

In Nigeria, a study conducted by Oluwole, Mohammed, and Akin (2016) revealed that knowledge, of cervical cancer screening among women was poor. Arulogun and Maxwell (2012) study on Perception and uptake of cervical cancer screening services among female nurses in UCH, Ibadan, Nigeria showed that utilization of cervical cancer screening services among female nurses was poor. Similarly, Aniebue, and Aniebue. (2010) Dhendup, and Tshering (2012) Abdallah et al. (2016) and Abdulkadir (2013) studies on awareness of cervical cancer screening amongst female students in university settings revealed poor knowledge and screening behaviors among female university undergraduates and graduates. However, Health professionals have been shown to have desired knowledge on cervical cancer screening. Kieti (2016) in Nairobi and Dulla, Daka, and Wakgari (2017) in Ethiopia study results showed that $94.0 \%$ and $77.1 \%$ of the respondents had good knowledge of CCS respectively. Furthermore, Awodele et al. (2011) study in Lagos University Teaching Hospital, Nigeria revealed that 91\% of nurses were knowledgeable of cervical cancer screening methods especially Pap smear.

Some other studies in and outside Nigeria on Attitude towards Cervical Cancer Screening however showed that 
both nurses and nursing students exhibited positive attitude towards CCS (AbdAllah et al., 2016; Awodele et al., 2016, Kieti, 2016; and Aniebue \& Aniebue, 2010). Similarly Ndikom and Ofi (2012) study in Ibadan, Nigeria, revealed that though participants were not aware of cervical cancer screening methods, they still believed that the practice was important since screening will help in early detection and treatment. In contrast, a study done by Ehiemere, Frank and Robin-Bassey (2015) on attitude and practice of female health workers in UPTH, Nigeria, revealed poor attitude as most of health workers testified that cervical cancer screening was embarrassing, expensive and not necessary.

In a similar study by HaddyBah (2016) using female nursing students at the University of Benin, Nigeria, result showed that only $6.6 \%$ of the students that heard about cervical cancer had been screened for it. Also Ibekwe (2015) study, using 100 clinical students (including nursing students) in Southern Nigeria, showed that only 7\% and $9 \%$ of the students had done cervical cancer screening in Delta State and Edo state respectively. Similarly, Ahmed, Sabitu, Idris and Ahmed (2013) study in Zaria reported that only $15.4 \%$ of participants were screened for cervical cancer, whereas Aniebue, and Aniebue. (2010) study showed that only 5.2\% of respondents had ever been screened for CC. Their conclusion pointed out the crucial to improve the uptake of preventive measures amongst the participants. If so then undergraduate nursing students' need to have accurate and updated knowledge, undertake practices of CCS.

The Purpose of the study was to ascertain:

- The level of knowledge on cervical cancer screening among female nursing students, in University of Calabar

- The attitude of female nursing students towards cervical cancer screening.

- The practice of cervical cancer screening among female nursing students.

\section{Materials and Methods}

A descriptive cross sectional design was considered most suitable for the study.

The study site was Department of Nursing, University of Calabar, Nigeria. The department is located within the University of Calabar close to the main library of the University. Participants' were female undergraduate nursing students of University which is the study area. The target population for this study was female nursing students of 300-500 Levels of the Department of Nursing Science (453). 100 and 200 levels were excluded because at these levels medical surgical nursing course which houses the topic of CCS is not taught. The sample size comprised of two hundred and twelve (212) randomly selected students who were in 300Level, 400Level and 500Level at the time of the study.

Table 1. Distribution of female students from 300 to 500 levels

\begin{tabular}{cccc}
\hline S/N & LEVEL & SET & NUMBER OF FEMALE STUDENTS \\
\hline 1. & 300 & $2015 / 2016$ & 146 \\
2. & 400 & $2014 / 2015$ & 171 \\
3. & 500 & $2013 / 2014$ & 136 \\
& Total & & 453 \\
\hline
\end{tabular}

Note. Data was gotten from the accessible population in each class.

The sample size for this research was two hundred and twelve (212) students from 300 to 500 levels. The sample was derived using Taro Yamane's formula:

$$
n=\frac{N}{1+N\left(e^{2}\right)}
$$

Where $\mathrm{n}=$ sample size

$\mathrm{N}=$ total population

$\mathrm{e}=$ constant $(0.05)$

$\mathrm{n}=221$ 
A researcher developed structured questionnaire tagged Undergraduate Nursing Students Knowledge, Attitude and Practice of Cervical Cancer Screening Questionnaire (UNSKAPCCSQ) was used to collect data. The instrument was made of four (4) Sections. Sections A: Contained introduction, instruction on how to respond and socio-demographic data from the respondents. Section B: Was on Knowledge of cervical cancer screening among female undergraduate nursing students. Section C: explored the Attitude of female undergraduate students towards cervical cancer screening, while Section D was on the Practice of cervical cancer screening among female nursing students. The instrument was face validated by experts in test and measurement. It was also subjected to reliability test using Crombach's Alpha method. The reliability coefficient obtained was 0.75.which showed high reliability of the instrument.

A letter was written to the Head of Department of Nursing Science seeking permission to carry out the study. The consent of the respondents was obtained freely without coercion. Minimal identifying information was obtained to ensure anonymity of participants. Students were also informed that any one not willing participate was free to opt out at any point in time. Data was collected by the 3 members of the research team. Copies of the instrument were administered and retrieved on the spot. Data was analyzed using frequencies and percentages

\section{Results}

Table 2. Participants' socio-demographic characteristics $(n=221)$

\begin{tabular}{|c|c|c|c|}
\hline Variables & Category & Frequency & Percentage (\%) \\
\hline \multirow{4}{*}{ Age } & $15-24$ & 94 & 42.5 \\
\hline & $25-34$ & 73 & 33.0 \\
\hline & $35-44$ & 54 & 24.4 \\
\hline & Total & 221 & 100 \\
\hline \multirow{4}{*}{ Level of study } & 300 Level & 97 & 43.9 \\
\hline & 400 Level & 102 & 46.2 \\
\hline & 500 Level & 22 & 10.0 \\
\hline & Total & 221 & 100 \\
\hline \multirow{5}{*}{ Marital status } & Single & 156 & 70.6 \\
\hline & Married & 62 & 28.1 \\
\hline & Divorced & - & - \\
\hline & Separated & 3 & 1.4 \\
\hline & Total & 221 & 100 \\
\hline \multirow{4}{*}{ Religion } & Christianity & 28 & 221 \\
\hline & Islam & - & - \\
\hline & Others & - & - \\
\hline & Total & 221 & 100 \\
\hline \multirow{3}{*}{ Ever had sexual intercourse } & Yes & 201 & 91.0 \\
\hline & No & 20 & 9.0 \\
\hline & Total & 221 & 100.0 \\
\hline \multirow{5}{*}{ Age at first intercourse } & Below 15 years & 67 & 30.3 \\
\hline & $16-20$ years & 26 & 11.8 \\
\hline & 21-25 years & 116 & 52.5 \\
\hline & $26-30$ & 12 & 5.4 \\
\hline & Total & 221 & 100 \\
\hline
\end{tabular}

Fieldwork, 2018. 
Table 2 shows demographic characteristics of the participants. The respondents of the study vary in terms of their socio-demographic indices covered in the investigation.

Table 3. Participants Knowledge of cervical cancer screening $(\mathrm{n}=221)$

\begin{tabular}{lll}
\hline Statements & Yes & No \\
\hline Cervical cancer screening reveals the possibility of one developing cervical cancer & 218 & 3 \\
& $(98.6 \%)$ & $(1.4 \%)$ \\
\hline Pap smear is used to tell if a woman has cancer & 206 & 15 \\
\hline Cervical cancer screening identifies the Human Papilloma Virus & $(93.2 \%)$ & $(6.8 \%)$ \\
\hline Cervical cancer can be screened using visual inspection with acetic acid & 106 & $(52 \%)$ \\
\hline All sexually active women should be screened for cervical cancer & $(48 \%)$ & 139 \\
\hline I know where I can go for cervical cancer screening & 82 & $(62.9 \%)$ \\
\hline
\end{tabular}

Field work, 2018.

The analysis in Table 3 shows that participants' level of knowledge on cervical cancer screening is good. Out of 221 participants, $218(98.6 \%)$ accepted that cervical cancer screening reveals the possibility of one developing cervical cancer while 3(1.4\%) said 'no', 206(93.2\%) said Pap smear is used to tell if a woman has cancer while $15(6.8 \%)$ did not accept this statement. This information is presented in Figure 2.

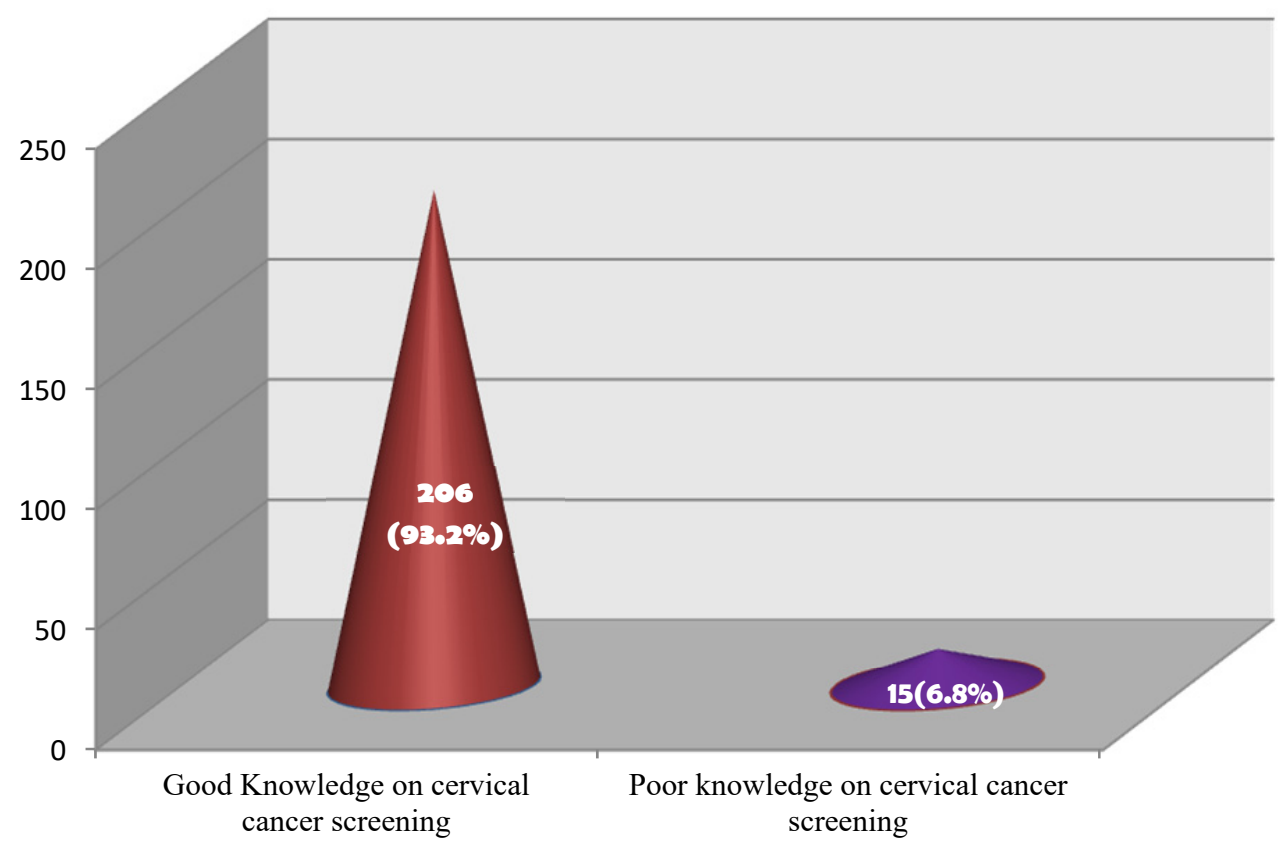

Figure 2. A conical bar chart showing summary of knowledge on cervical cancer screening among undergraduate nursing students 
Table 4a. Attitude of female undergraduate nursing students towards cervical cancer screening $(n=221)$

\begin{tabular}{|c|c|c|c|c|}
\hline Statements & SA & $\mathbf{A}$ & $\mathbf{D}$ & SD \\
\hline \multirow[t]{2}{*}{ I am healthy and do not need cervical cancer screening } & 2 & 12 & 187 & 20 \\
\hline & $(0.9 \%)$ & $(5.4 \%)$ & $(84.6 \%)$ & $(9 \%)$ \\
\hline \multirow[t]{2}{*}{ I am too busy to go for such check ups } & 108 & 26 & 79 & 9 \\
\hline & $(48.9 \%)$ & $(11.3 \%)$ & $(35.7 \%)$ & $(4.1 \%)$ \\
\hline \multirow[t]{2}{*}{ I am not interested in cervical cancer screening because doing it is embarrassing } & 166 & 3 & 52 & - \\
\hline & $(75.1 \%)$ & $(1.4 \%)$ & $(23.5 \%)$ & \\
\hline \multirow[t]{2}{*}{ I do not need cervical cancer screening because I have one sexual partner } & 154 & 5 & 51 & 11 \\
\hline & $(69.7 \%)$ & $(2.3 \%)$ & $(23.1 \%)$ & $(5 \%)$ \\
\hline \multirow[t]{2}{*}{ I do not consider going for cervical cancer screening because it is too expensive } & 139 & 23 & 59 & - \\
\hline & $(62.9 \%)$ & $(10.4 \%)$ & $(26.7 \%)$ & \\
\hline \multirow[t]{2}{*}{ I have a feeling of insecurity when attempting screening test } & 54 & 125 & 21 & 21 \\
\hline & $(24.4 \%)$ & $(56.6 \%)$ & $(9.5 \%)$ & $(9.5 \%)$ \\
\hline \multirow[t]{2}{*}{ I don't consider it necessary } & - & - & 192 & 29 \\
\hline & & & $(86.9 \%)$ & $(13.1 \%)$ \\
\hline
\end{tabular}

Fieldwork, 2018.

Participants' responses in this section were collapsed into 2 (agree and disagree). The scores for strongly agree and agree were merged into agree, representing Negative attitude while those of strongly disagree and disagree were collapsed into disagree and signifies participant's positive attitude towards cervical cancer screening. This summary is given in Table $4 \mathrm{~b}$. The sums of scores were again computed and the final summary of participants' attitude concerning cervical cancer screening is presented in Figure 3.

Table 4b. Summary of attitude of female undergraduate nursing students towards cervical cancer screening $(\mathrm{n}=$ 221)

\begin{tabular}{lcc}
\hline Statements & Agreed & Disagree \\
\hline I am healthy and do not need cervical cancer screening & 14 & 207 \\
I am too busy for cervical cancer screening & $(6.3 \%)$ & $(93.6 \%)$ \\
& 134 & 88 \\
I do not like cervical cancer screening because it is embarrassing & $(60.2 \%)$ & $(39.8 \%)$ \\
& 169 & 52 \\
I do not need cervical cancer screening because I have one sexual partner & $(76.5 \%)$ & $(23.5 \%)$ \\
& 159 & 62 \\
I do not go for cervical cancer screening because it is too expensive & $(72 \%)$ & $(28.1 \%)$ \\
I have a feeling of insecurity when attempting cervical cancer screening test & 162 & 59 \\
Cervical cancer screening is not necessary & $(73.3 \%)$ & $(26.7 \%)$ \\
& 179 & 42 \\
\hline
\end{tabular}

Field work, 2018. 


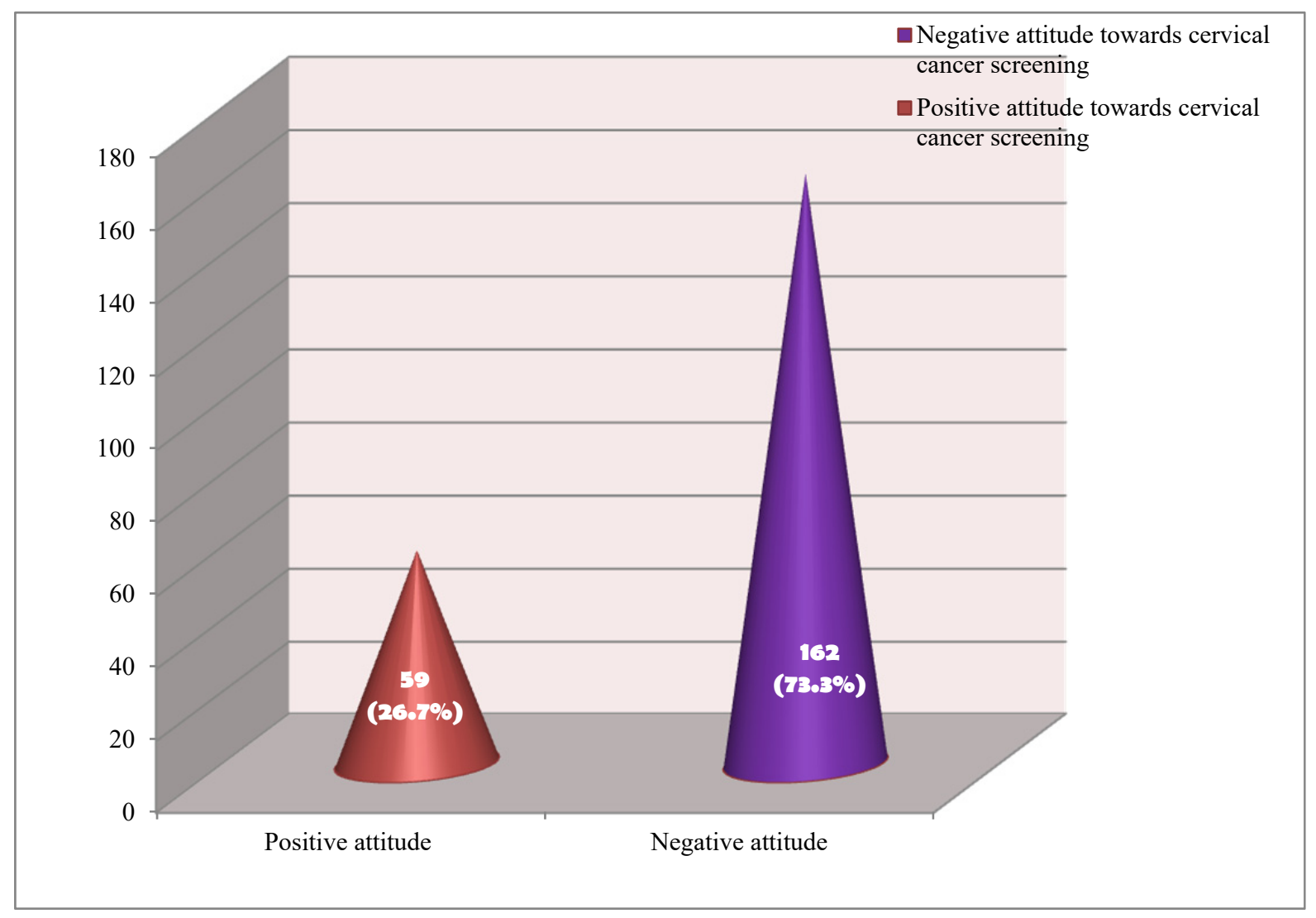

Figure 3. A conical bar chart showing overall summary of participants' attitude towards cervical cancer screening

Table 5. Practice of cervical cancer screening among female undergraduate nursing students $(n=221)$

\begin{tabular}{lcc}
\hline Statements & Yes & No \\
\hline I have been screened for cervical cancer & 11 & 210 \\
I go for cervical cancer screening every three years & $(5 \%)$ & $(95.5 \%)$ \\
& 2 & 219 \\
I was up to 18 years when I got screened for cervical cancer & $(0.9 \%)$ & $(99.1 \%)$ \\
I had my first sexual intercourse when I got screened for cervical cancer & - & 221 \\
& - & $(100 \%)$ \\
I was screened for cervical cancer by a health professional & & 221 \\
& 11 & 210 \\
\hline
\end{tabular}

Field work, 2018.

As indicated in Table 5, out of 221 participants who participated in the study, 11(5\%) accepted to have had themselves screened, while $210(95.5 \%)$ said 'no'. As regards going for cervical cancer screening every three years, only $2(0.9 \%)$ said 'yes' while $219(99.1 \%)$ said they do not. 


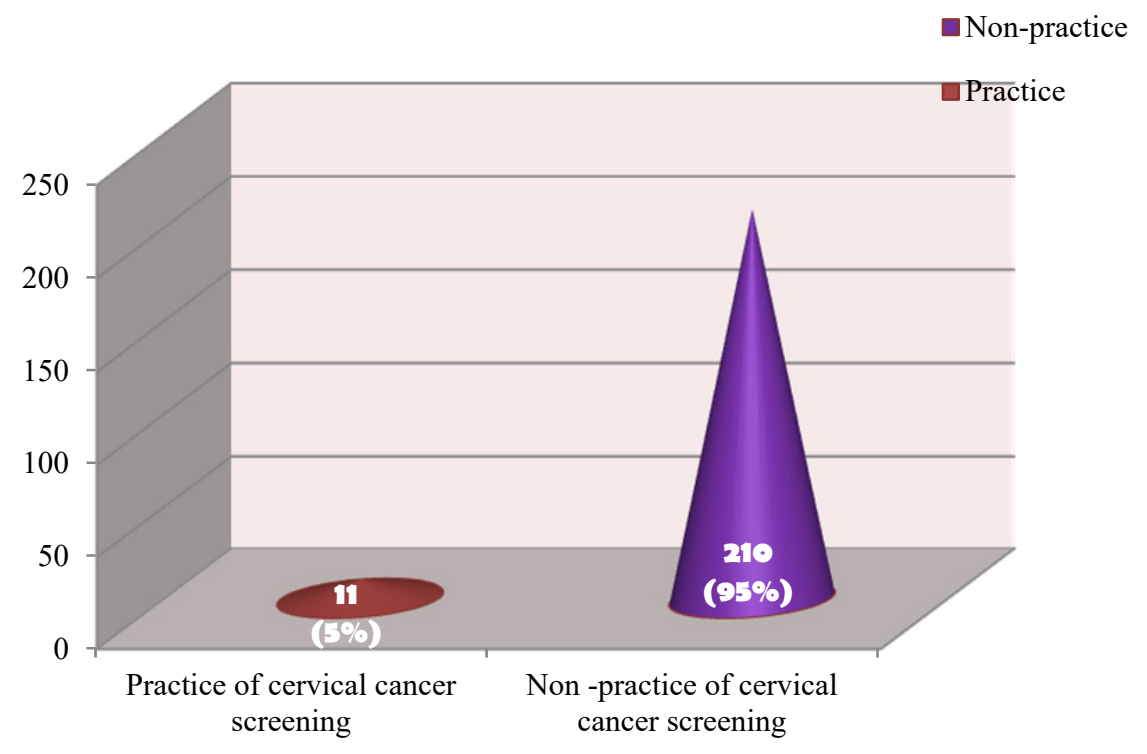

Figure 4. A conical bar chart showing summary of participants' practice of screening

\section{Discussion of Findings}

Majority of the female undergraduate nursing students had good knowledge of cervical cancer screening; the procedures, methods (especially Pap's smear) and where to seek for the services. A few had poor knowledge in respect of the use of visual inspection with acetic acid to detect the presence of cervical cancer. This could be attributed to the fact that the method is not as popular as Pap's smear. The findings agree with that of (Kieti, 2016; Dulla et al., 2017; Awodele, 2011). However, this result is in contrast with that of AbdAllah et al. (2016), Arogun and Maxwell (2012), Aniebue and Aniebue (2013) and Dhendup (2012) which showed that participants had poor knowledge of screening measures. It is important to take cognizance that while keiti, Dulla's and Awodele's studies involved registered nurses, AbdAllah's, Aniebue and Aniebue, and Dhendup involved nursing students who were yet to graduate. This could be responsible for the differences in their results. In this study, nursing students' level of knowledge was good; this could be attributed to the high level of awareness being created by NGO's in the media in cross river state and Nigeria government as a whole. However since some students knowledge was poor in some areas as shown in the analysis, it becomes necessary for the nursing training institutions especially department of nursing Unical to intensify and improve their efforts in teachings in respect to CCS so as to buttress the government and NGOs effort.

The findings further showed that most female undergraduate nursing students displayed negative attitude towards cervical cancer, some claiming to be too busy to go for the screening, while others saw the screening as not necessary. This finding is buttressed by that of Ehiemere et al. (2015) whose result showed poor attitude of female health workers towards cervical cancer screening. This finding shows that having head knowledge of a thing does not guarantee a favorable attitude towards that same thing. In contrast to this finding, AbdAllah et al. (2016) revealed that majority of nursing students exhibited willingness for screening and recommend it for those at risk of cervical cancer. Furthermore this study revealed that very few female nursing students had been screened for cervical cancer. This result is consistent with that of HaddyBah (2016) among female nursing students in Benin, which showed that most nursing students had not been screened for cervical cancer even though they were sexually active and knew where to go for screening exercise. This could be attributed to the high cost of cervical cancer screening and the invasive procedure required for the screening. Similarly Ibekwe (2015) reported that only $7 \%$ of the clinical students in his study were screened for cervical cancer. It is evident from these results that the female undergraduate nursing students in University of Calabar know about cervical cancer screening but this knowledge did not necessarily translate to their change of attitude and practice towards CCS.

\section{Conclusion}

High level of Knowledge of Cervical cancer screening among the female nursing students did not translate to positive attitude and practice. It is recommended that cervical cancer screening education should be intensified for 
nursing students. CCS should be a mandatory screening for all newly admitted female undergraduate in the university. Nursing students should be made to participate actively in raising awareness on cervical cancer screening and management.

\section{Implication to Nursing Education}

Increasing incidence and high mortality rate associated with cervical cancer screening makes the uptake of the exercise very necessity. It becomes important for undergraduate nursing students to be knowledgeable and have positive attitude for the practice of screening for cervical cancer. Nurse Educators/Lecturers therefore need to engage methods of teaching whereby nursing students are not only taught to acquire knowledge but for such knowledge to translate to change in behavior. Nursing students should be trained to appreciate their health preventive measures and be made to understand that they need to stay healthy thereby be able to encourage other women and the society at large to do same. Most times change in attitude and behavior can easily be influenced when relevant people share experiences or teach with practical examples and experiences.

Nursing students as custodians of the future nursing profession should be taught about cervical cancer screening, trained to be familiar with the different methods of CCS, be positive about it and be encouraged to practice it. Only then can they effectively health educate other women and society at large to undertake same which will ultimately reduce the menace of cervical cancer in Nigeria and CRS in particular.

\section{Recommendations}

1) Cervical cancer screening (CCS) should be part of the routine medical examination for female nursing students who have gain admission to the University every year. This exposure will not only translate to having healthy undergraduates but will also imply that screening for cancers is as necessary as screening for TB, HIVHBV etc., and also inculcate in them the attitude of medical examination and checkups.

2) Nursing students who are sexually active should be encouraged to continuously screen for cervical cancer.

3) The cost of cervical cancer screening should be subsidized by the government to overcome the barrier caused by the cost.

\section{Suggestions for Further Studies}

This research should be carried out in other departments and schools of nursing within the south south geopolitical zone of Nigeria involving larger sample size for generalizations to be made.

\section{References}

AbdAllah, A. A. A., Hummeida, M. E., \& Elmula, I. M. F. (2016). Awareness and Attitudes of Nursing Students towards Prevention of Cervical Cancer. Cervical Cancer, 1, 107. https://doi.org/10.4172/ccoa.1000107

Abdulkadir, I. (2013). Level of Knowledge toward Human papillomavirus/cervical cancer and practice of papanicoloau test screening among female Addis Ababa university students in Ethiopia (master's thesis, California state university, Northridge California).

Adewale, A., Isa, M., Dareng, E., Bamisaye, P., Jedy- Agba, E., ... Adebamono, C. (2016). Qualitative study of barriers to cervical cancer screening among Nigerian Women. British Medical Journal Open, 6(i). https://doi.org/10.1136/bmjopen-2015-008533

American Cancer society. (2016). Cervical Cancer. Retrieved from https//www.cancer.org/cancrer/cervical-cancer.html

American Cancer society. (2018). Key statistics for cervical cancer. Retrieved from https://www.cancer.org/.cancer/cervical-cancer/arbour/key-statistics.html.

American College of Obstetrics and Gynaecologists. (2014). Cervical Caner. Retrieved from https://www.acog.org/cervical-cancer-1?ismobileset.

American Society of Clinical Oncology (ASCO). (2018). Annual Meeting ASCO. Annual Meeting ASCO in Chicago, IL from June 1-5, 2018.

American Society of Clinical Oncology. (2018). Optimization of cervical cancer screening and triage in low-Resource settings. Journal of Global Oncology, 4(1), 1-2. https://doi.org/10.1200/JGO.18.00192

Aniebue, P. N., \& Aniebue, U. U. (2010). Awareness and practice of cervical cancer screening among female undergraduate students in a Nigerian university. $J$ Cancer Educ., 25, 106-8. PubMed. https://doi.org/10.1007/s13187-009-0023-z 
Arulogun, O., \& Maxwell, O. (2012). Perception and utilization of cervical cancer screening services among female nurses in University College Hospital, Ibadan, Nigeria. Pan Afr Med J., 11, 69.

Awodele, O., Adeyomoye, A. A., Awodele, D. F., Kwassh, I. O., Awodele, I. O., \& Dolapo, D. C. (2011). A study on cervical cancer screening amongst nurses in Lagos University Teaching Hospital, Lagos, Nigeria. $J$ Cancer Educ., 26(3), 497-504. https://doi.org/10.1007/s13187-010-0187-6

Ayinde, O. A., \& Omigbodun, A. O. (2003). Knowledge, attitude and practices related to prevention of cancer of the cervix among female health workers in Ibadan. $J$ Obstet Gynaecol, 23(1), 59-62. https://doi.org/10.1080/0144361021000043272

Bray, F., Jonal, A., Grey, N., Ferlay, J., \& David, F. (2012). Global Cancer Transitions According to the Human Development Index (2008-20230) a population base study. The Lancet Oncology, 13(8), 790-801. https://doi.org/10.1016/S1470-2045(12)70211-5

Campana. (2017). Cervical Cancer Screening. Geneva Foundation for Medical Educational Research.

Cancer Research UK. (2014). Treatment if you have abnormal cervical cells. Retrieved from https://www.cancerresearchuk.org/about-cance/type/cervicalcancer/smears/treatment-if-you-haveabnormalcervical-cells

Cancer Research UK. (2017). Our Policy on cervical cancer screening. Retrieved From https://www.Cancersearchuk.org/about-us/we-develop-policy/our policy on-early-diagnosis

Cancer Treatment Centres of America. (2017). Cervical Cancer. Retrieved from https://www.Cancercenter.co/cervical.Cancer/diagnostics-and-treatment/

Center for Disease Control and Prevention. (2017). Screening Recommendations and Consideration. Retrieved from https://www.edc.gov/cancer/cervicalhpv

Cervical Cancer Action. (2011). A new Era for Cervical Cancer prevention. Retrieved from https://www.cervicalcanceraction.org/pubs/CCareportcardlow-rest-2015.pdf

Dhendup, T., \& Tshering, P. (2014). Cervical cancer knowledge and screening Behaviors among female university graduates of year 2012 attending national Graduate orientation program, Bhutan. BMC Women's Health, 14(1), 44. https://doi.org/10.1186/1472-6874-14-44

Dulla, D., Daka, D., \& Wakgari, N. (2017). Knowledge about Cervical Cancer Screening and Its Practice among Female Health Care Workers In Southern Ethiopia: A Cross-Sectional Study. International Journal of Women's Health, 9, 365-372. https://doi.org/10.2147/IJWH.S132202

Ebughe, G. A., Ekanem, I. A., Omoronyia, O. E., Omotoso, A. J., Ago, B. U., Agan, T. U., \& Ugbem, T. I. (2016). Incidence of Cervical Cancer in Calabar, Nigeria. Journal of Cancer and Tumor International, 3(2), 1-13. https://doi.org/10.9734/JCTI/2016/23512

Ehiemere, I. O., Maureen, D. F., \& Robinson-Bassey, G. C. (2016). Attitude and practice of cervical cancer screening among female health workers in university of Port-Harcourt teaching hospital. Rivers State Journal of Research in Nursing and Midwifery (JRNM), 4(4), 072-082. http:/dx.doi.org/10.14303/JRNM.2015.125

Haddybah. (2016). Knowledge and Practice of Cervical Cancer Screening among Female Student Nurses in University of Benin, Nigeria.

Ibekwe, U. R. (2015). Comparative Assessment of Knowledge, Attitude and Practice of Cervical Cancer and it's Screening among Clinical Students in Southern Nigeria. The Nigerian Health Journal, 15(2).

International Agency for Research on Cancer. (2014). A practical manual on visual screening for cervical neoplasia. Retrieved from https://screening.iarc.fr/viavilichap.lphp?lang=1

International Agency for research on Cancer. (2018). FIGO. Staging of cervicalcarcinomas. Retrieved from https://www.screening.iarc.fr/viavillappendix.php

Kieti, S. N. (2016). Knowledge, Attitude And Practices On Cervical Cancer Screening And Prevention Methods Among Nurses At Two Nairobi Hospitals In Kenya. Retrieved from https://hdl.handle.net/10500/22760(DISSERTATION)

Modibbo, F. I., Dareng, E., Bamisaye, P., Jedy-Agba, E., Adewole, A., Oyeneyin, L. et al. (2016). Qualitative Study of Barriers to Cervical Cancer Screening Among Nigerian Women. BMJ Open, 6(1), e008533. PMID: 28464289. https://doi.org/10.1136/bmjopen-2015-008533 
National Cancer Institute. (2015). Cervical Cancer-Patient version. Retrieved from https://www.cancer.gov/types/cervical

Ndikom, C., \& Ofi, B. (2012). Awareness, perception and factors affecting utilization of cervical cancer screening services among women in Ibadan, Nigeria: A qualitative study. Reprod Health, 9, 11. https://doi.org/10.1186/1742-4755-9-11

Oluwole, E. O., Mohammed, A. S., Akinyinka, M. R., \& Salako, O. (2016). Cervical Cancer Awareness and Screening Uptake among Rural Women in Lagos, Nigeria. Journal of Community Medicine and Primary Health Care, 29(1), 81-88.

Oyeneyin, O. et al. (2016). Qualitative study of barriers to cervical Cancer Screening among Nigerian women. BMJ Open, 6(1). https://doi.org/10.1136/bmjopen-2015-008533

Randall, T. C., \& Ghebre, R. (2016). Challenges in Prevention and Care Delivery for Women with Cervical Cancer in Sub-Saharan Africa. Front Oncology, 6, 160. https://doi.org/10.3389/fonc.2016.00160

Rural Health Information Hub. (2018). Barriers to Cervical Cancer Screening Among Rural Appalachian Women. Retrieved from https://www.ruralhealthinfo.org/cervical-cancer-screening

Sasieno, P., Castanon, A., \& Cuziek, J. (2009). Effectiveness of cervical cancer screening with age. British Medical Journal, 33(9). doi.10.1136/bmj.2968

Siferlin. (2014). FDA Approves First Test for Primary cervical cancer screening. Time Magazine. Retrieved from http://www.time.com/76352/fda-cervical-cancer-screening

Small, W. Jr, Bacon, M. A., \& Bajaj, A. (2017). Cervical cancer: A global health crisis. American Cancer Society, 123(13), 2404-2412. Epub. https://doi.org/10.1002/cncr.30667

World Health Organization International Agency for Research on Cancer (IARC). (2008). Globocan 2008 Report. Lyon: International Agency for Research on Cancer.

World Health Organization. (2013). New guide to prevent and control cervical cancer. Retrieved from https://www.who.int/immunization/hpv/learn

World Health Organization. (2018). Cervical Cancer. Retrieved from https://www.who.int/cancer/prevention/diagnosis-screening/cervicalcancer/en

\section{Copyrights}

Copyright for this article is retained by the author(s), with first publication rights granted to the journal.

This is an open-access article distributed under the terms and conditions of the Creative Commons Attribution license (http://creativecommons.org/licenses/by/4.0/). 